\title{
Review of Various Dimensions of Contrastive Studies by Bożena Cetnarowska, Marcin Kuczok and Marcin Zabawa (eds.), Katowice: Wydawnictwo Uniwersytetu Śląskiego, 2016
}

\author{
Ewelina Mokrosz and Sławomir Zdziebko \\ John Paul II Catholic University of Lublin, Poland
}

\begin{abstract}
The paper constitutes a review of a collection of articles entitled 'Various Dimensions of Contrastive Studies' published by Wydawnictwo Uniwersytetu Śląskiego in 2016 under the editorship of Bożena Cetnarowska, Marcin Kuczok and Marcin Zabawa. Each section of the review contains a critical evaluation of one paper found in the volume. We conclude that although the volume could benefit from more direct discussion pertaining to the methodology of contrastive studies, each of the articles constitutes a significant contribution to its particular domain and is worth-recommending to the reader who desires to keep track of the developments within different areas of the study of language.
\end{abstract}

Keywords: contrastive studies, language variation, parameters, vocabulary, discourse studies

\section{Introduction}

As much as one might agree with Knight's (2016: 14) contention accompanying his discussion of the Chomskyian views on the origin of language that "what other people call "language" - the constellation of shared understandings known as, say, "French" or "Swahili" - does not exist...', most linguists, now and in the past, would also agree that if a given theory of language is to be complete, it must be informed by data from as many systems as possible. Hence, philological studies were decidedly comparative at their very heart for the better part of the 19th and much of the 20th century. That comparative linguistic studies have not lost their raison d'être and their appeal in the first decades of the 21st century has been emphasised by the authors of the volume entitled 'Various Dimensions of Contrastive Studies' published by Wydawnictwo Uniwersytetu Śląskiego in 2016. The common denominator for most of the papers compiled under the editorship of Bożena Cetnarowska, Marcin Kuczok and Marcin Zabawa is that the conclusions about the validity of the tested hypotheses they reach are based on a comparison of 
data from more than one linguistic system. The aim of this review is to evaluate each article in the volume from the point of view of its contribution to the respective area of philological studies it pertains to, but also from the point of view of its contribution to philology as an essentially comparative discipline.

Similarly to the editors of the volume, we have decided to arrange the body of the review into three major sections. In Section 2 we take a closer look at the papers found in the part of the volume entitled 'Contrastive Studies of Language Structures'. Section 3 focuses on part 2 of the volume: 'Contrastive Studies of Words and their Meanings'. Section 4 evaluates the contributions found in part 3: 'Contrastive Linguistics beyond Language Forms'. Section 5 offers a general evaluation and concluding remarks.

\section{Contrastive studies of language structures}

The first part of the book is concerned with strictly formal aspects of linguistic research and concentrates on the cross-linguistic differences that may be captured and modelled by formal generative frameworks. The contributions by Anna Bloch-Rozmej and Artur Kijak focus on the differences attested in the phonological systems of different Germanic languages. The chapters by Maria Bloch-Trojnar, Bożena Cetnarowska and Anna Malicka-Kleparska revolve around various aspects of the morpho-syntax of languages such as Irish, English, Polish Russian and Old Church Slavonic. The contribution by Bożena Rozwadowska and Ángel JiménezFernández discusses the Information Structure of Dative Experiencer constructions in Spanish, English and Polish. Finally, the contribution by Konrad Szcześniak is a comparison of the analytical possibilities of two formal frameworks: the derivational generative framework and the mono-stratal declarative Construction Grammar.

\subsection{Domain structure conditions in Vilamovian and English}

Anna Bloch-Rozmej's contribution employs the framework of Principles and Parameters to compare the phonotactics of two West Germanic languages: English and Vilamovian. The latter is a geographically isolated dialect of Germanic related to Frisian and spoken in the city of Wilamowice in Southern Poland (close to the city of Bielsko Biała). The version of the Principles and Parameters assumed by the author, Government Phonology (Kaye, Lowenstamm and Vergnaud 1990; Harris 1994; Bloch-Rozmej 2008), is a framework designed to account for the distribution of linguistically relevant information within the speech signal, or, more precisely, within phonological domains (typically corresponding to words). There are three types of constituents that form such domains: onsets, rhymes and nuclei. Each such constituent may be, at most, binary branching.

As a version of Principles and Parameters, Government Phonology is naturally designed to account for the cross-linguistic differences in phonotactics. The complexity of constituents boils down to a limited set of binary choices: a language may or may not allow its onsets, nuclei and rhymes to branch. 
If a language allows its onsets to branch, it contains clusters of rising sonority such as /tr/, $/ \mathrm{pr} /, / \mathrm{kl} /$, etc. The positive setting on the branching nuclei parameter allows a language to contrast short vowels (non-branching nuclei) with long vowels (branching nuclei). A language that allows branching rhymes possesses coda-onset clusters of falling sonority such as $/ \mathrm{rt} /, / \mathrm{lp} /$, /nd/, etc. In addition, a language may or may not allow its final nuclei to remain unpronounced ${ }^{1}$ and may or may not allow the unpronounced or empty nuclei to license consonantal clusters.

In her comparative description the author concludes that English and Vilamovian differ only in that the latter, but not the former, allows its final unpronounced nuclei to license complex onsets and as a result possesses domains terminating in clusters of rising sonority, e.g. the word engl/engl/ 'angel'.

Since it is one of the first accounts of the phonotactics of Vilamovian, the chapter contains a unique contribution to West-Germanic dialectology. It also illustrates how the theory that assumes the existence of universal principles and parameters and language-specific parametric settings can be applied to systematically account for the similarities and differences between linguistic systems.

At the same time, as a contribution to a volume whose subject matter is the dimensions of contrastive studies, the chapter could contain more of a discussion about the nature of parameters and parametric settings. How are parametric settings decided at language acquisition? Are there inborn default parametric settings or are speakers born with the parameter settings unspecified? Are phonological parameters completely independent of each other or are they arranged in hierarchies of dependencies? The contribution of this chapter to the methodology of contrastive linguistic studies would be clearer if such issues had been addressed.

\subsection{Sonorant expansion in English and German}

There are two dimensions of contrast addressed in Artur Kijak's contribution. The first of them is a comparison of data from two different languages: English and German. The second one is a comparison of the properties of three different processes found in these languages: the formation of syllabic consonants, vowel syncope in English and vowel-zero alternations found in German.

The author focuses on the similarities between the three processes. All of them require the presence of sonorant consonants and the shwa vowel and all of them involve prosodically weak contexts.

The framework assumed by the author is the Strict CV version of Government Phonology (see Scheer 2004; Scheer and Zikova 2010). Unlike Standard Government Phonology, it assumes that constituents do not branch and that phonological domains are composed of sequences of onsets or C-positions and nuclei or V-positions. The choice of framework allows the author to provide a natural geometric account of the syllabicity of sonorants: in words such as English sudden /sıdn/ or German wetten /vetn/ 'bet' the final sonorant occupies the final C-

1 Each domain is assumed to terminate in a nucleus and each domain-final consonant is assumed to be syllabified in the onset. 
position, spreads onto the preceding V-position and is allowed to function as a syllable nucleus. More importantly, such a spreading is possible only if the preceding vowel is a schwa. According to the author, this is due to the weakness of the schwa vowel. Whenever the sonorant annexes the preceding V-position, the schwa is not realized.

In addition, it is often the case that the word-final nasal spreads further to the left onto the preceding obstruent and acquires its place of articulation. This situation is very frequent in German, where citation forms such as Wagen /vargən/ 'car' are typically pronounced as /vargy/ etc. The property of sonorants to spread to the neighbouring positions is due to the influence of a prosodically weak positions (coda) where the sonorant has problems maintaining its own place of articulation. The situation is, however, different when vowel initial affixes are concatenated with the stem and the nasal is syllabified in the onset. In such a case neither syllabic consonant nor place assimilation are attested and Wagner 'carriage' is pronounced /vakknə/, with the vowel dropped and with Final Obstruent Devoicing. According to the author, the dropping of the schwa in forms such as Wagner/vaknə/ 'carriage' quite clearly resembles vowel syncope attested in English in words such as chocolate/t $\int \mathrm{pk}(ə)$ lət/ or separate /scp(ə)rət/, in that the condition for vowel syncope in both cases is the presence of a sonorant followed by a pronounced vowel to the right of the alternation site.

This chapter focuses on the similarities between the application of the three processes in the two languages and hardly addresses the differences between them. Such differences clearly exist. For example, only English allows for the formation of syllabic consonants at the beginning of words. The words until may be realised as / $\mathrm{n}$ tıl/, /əntıl/ or /ntrl/. On the other hand, the place assimilation between the nasal and preceding obstruent observed in forms such as Wagen /vargy/ is much more frequent in German and definitely not attested in many speakers of standard English. Unfortunately, the reader does not learn from the chapter how such cross linguistic differences are modelled by the Strict CV framework. We may infer that formally, one would simply have to do with the absence of the spreading of sonorants in certain contexts. However, the question as to whether such an absence is merely an accidental 'absence of a rule', some specific parametric setting or whether it stems from some principled condition on the licensing of syllabic consonants remains unaddressed.

\subsection{The semantics of aspect and nominalization in English and Irish}

In her contribution Maria Bloch-Trojnar contrasts the Aktionsart properties of two crosslinguistically common varieties of nominals derived from verbs: verbal nouns, e.g. running, describing, and deverbal nouns, e.g. a run, a description, in English and Irish.

Both languages possess verbal and deverbal nouns. In terms of event structure and lexicosemantic verbal classification, verbal nominals are based on processual aspect-variable verbs (verbs that may be classified as either [+Perfective] or [-Perfective]). Deverbal nouns, on the other hand, are based on verbs that lack the process subevent and are aspectually [+Perfective]. In some cases, in Irish deverbal nouns may also be based on [-Perfective] verbs.

Another property that the verbal and deverbal nouns in the two languages share is that they preserve the Aktionsart (and event structure) properties of the base verbs. English verbal nouns 
are non-count and usually express the unfolding, processual nature of the nominalised event. Alternatively, one could say that English verbal nouns present the event from the inside without recognising its boundaries. Deverbal nouns in English take an external perspective on the nominalised event with the inception, culmination and result of the event exposed. This is expected if the stems the deverbal nouns are based on are classified as [+Perfective]. As may be expected, deverbal nouns are normally count.

Irish verbal nouns reflect the durative character of the nominalised event by taking the unbounded perspective on the situation. This is not surprising once we know that they are typically based on imperfective verbs and that imperfective aspect in Irish is strictly connected to the unboundedness of an event. Deverbal nouns, on the other hand, usually denote bounded events, which are normally instantiated by punctual verbs in Irish. Deverbal nouns based on imperfective verbs typically denote bounded portions of homogenous or atelic eventualities.

This chapter, couched within the framework of Lexeme Morpheme Base Morphology (LMBM, Beard 1995; Beard and Volpe 2005; Bloch-Trojnar 2013), provides a very solid ground for the theoretical discussion which the author does not take full advantage of. In fact, LMBM predicts that the output of transposition preserves the Aktionsart properties of the verbal base. The theory assumes that the inner aspectual properties are defined by inherent lexico-semantic features such as [+/-Dynamic], [+/-Durative] and [+/-Consequent State], which, crucially, cannot be affected by the operation of transposition. Thus, a situation in which a verbal/deverbal noun would not preserve the properties of the verbal base would be surprising and problematic for the framework.

The second important theoretical point is the parallel drawn in the two languages between the outputs of certain verbal inflectional operations and the output of transposition. To be more precise, in English only processual verbs, but not those verbs which lack the process subevent, give rise to present participles. ${ }^{2}$ Note that verbal nouns are also only derived from processual verbs. In Irish, the presence of the processual subevent is also a necessary condition for the formation of present participles and verbal nouns. The parallel between inflectional and derivational processes is all but surprising from the point of view of LMBM. The theory assumes a Unitary Grammatical Function Hypothesis (see Beard and Volpe 2005: 191) which says that the lexical derivational component of the grammar, as well as the syntactic inflectional component in a given language, operate on the same grammatical functions. The existence of the same constraints on certain derivational and inflectional operations is, therefore, to be expected.

In sum, the aspects of transposition in the two languages analysed in the chapter may be viewed as strong arguments in favour of the Morpheme-Lexeme Base Morphology architecture. A fact which could be more strongly highlighted and taken advantage of.

\footnotetext{
2 Present participles are considered to be an inflectional category by the proponents of the LMBM approach.
} 


\subsection{Contrasting different morphosyntactic choices in English and Polish noun phrases}

Bożena Cetnarowska's chapter discusses the patterns of modification of eventive nominals in Polish and English. To be more precise, this contribution compares the means by which the two languages introduce arguments of transitive and intransitive eventive nominals.

English introduces arguments of the relevant nouns by means of pre- and post-nominal genitive constructions, by-phases, relational adjectives, $N+N$ compounds and locative prepositional adjuncts. Polish uses post-nominal genitives, relational adjectives and the Polish equivalent of $b y$-phrases, i.e. przez-phrases. All these possibilities are summarized and exemplified in (1).

\begin{tabular}{|c|c|c|c|}
\hline (1) & & English & Polish \\
\hline a. & Pre-nominal genitive & women's fight & $\mathrm{n} / \mathrm{a}$ \\
\hline b. & Post-nominal genitive & the fight of women & $\begin{array}{l}\text { sprzedaż samochod-u } \\
\text { sale.NOM.SG car-GEN.SG } \\
\text { 'the sale of the car' }\end{array}$ \\
\hline c. & Relational adjectives & governmental attempts & $\begin{array}{ll}\text { papiesk-a } & \text { wizyt-a } \\
\text { papal-NOM.SG } & \text { visit-NOM.SG } \\
\text { 'papal visit' } & \end{array}$ \\
\hline d. & by/przez-phrases & $\begin{array}{l}\text { the building of the great pyramids } \\
\text { by the ancient Egyptians }\end{array}$ & $\begin{array}{l}\text { sprzedaż samochod-u } \\
\text { sale.NOM.SG car-GEN.SG } \\
\text { przez Jan-a } \\
\text { by John-GEN.SG } \\
\text { 'the sale of the car by John' }\end{array}$ \\
\hline e. & $N+N$ compounds & student talking & $\mathrm{n} / \mathrm{a}$ \\
\hline f. & $\begin{array}{l}\text { Locative prepositional } \\
\text { phrases }\end{array}$ & the pope's visit to Cuba & $\mathrm{n} / \mathrm{a}$ \\
\hline
\end{tabular}

Although Polish seems to allow fewer options, one should keep in mind that Polish relational adjectives may serve as either pre-modifiers or post-modifiers in noun phrases. Thus the phrase wizyt-a papiesk-a visit-NOM.SG papal-NOM.SG 'papal visit' is as acceptable as papiesk-a wizyta papal-NOM.SG visit-NOM.SG 'papal visit'. This is not the case in English where ${ }^{\star}$ attempts governmental is not a well-formed NP.

In her chapter Cetnarowska undertakes a corpus study to determine which means of introducing arguments presented in (1) are preferred with the English nouns arrival and visit, as well as their rough Polish equivalents przyjazd and wizyta. She quotes data from the Corpus of Contemporary American English (COCA) as well as the National Corpus of Polish (NKJP) and Google.

When it comes to the nominal arrival based on the intransitive (unaccustaive) verb arrive, in COCA its sole argument is typically realised as the pre-head genitive in which case it refers to a specific animate entity (the president's arrival). The post-nominal of-genitive is much less frequent and typically dictated by the prosodic and informational weight of the argument (the

3 The paper uses the following set of abbreviations in the glosses: A - adjective, ACC. - accusative, ADV. - adverb, DAT. - dative, DIM. - diminutive, GEN. - genitive, INF. - infinitive, INST. - instrumental, LOC. - Locative, $\mathrm{N}$ - noun, NOM. - nominative, PL. - plural, PTCP. - participle, SG. - singular, TH - thematic vowel. 
arrival of the President Yeltsin of Russia). The realisation of the argument as an $N+N$ compound is unattested, while the use of the relational adjective presidential arrival is confined to headlines and Tweeter feeds, where economy of expression is the general principle.

The nominal visit related to the transitive verb is expected to license two arguments. Cetnarowska's COCA study revealed that the internal argument of the noun visit is not introduced by a pre- or post-nominal genitive construction, but rather as an adjunct prepositional phrases (the papal visit in Santiago). The genitive constructions are reserved for the subject or external argument (the pope's visit, the scheduled visit of the Pope John Paul II). The latter is, again, less popular and restricted to 'heavy' NPs. Even less frequent is the use of by-phrases (visit by Pope John Paul II). The use of the relational adjective papal is common in more formal registers and written discourse.

The sole argument of the Polish nominal przyjazd 'arrival' is typically realised as the postnominal genitive (przyjazd prezydent- $a$ arrival.NOM.SG president-GEN.SG 'the arrival of the president'). Occasionally, one finds the subject realised by means of the relational adjective (papiesk-i przyjazd papal-NOM.SG arrival.NOM.SG 'papal arrival').

As noted by Cetnarowska (p. 81) the noun wizyta 'visit' is not a deverbal noun in Polish. The verb wizytować means rather 'to inspect' or 'to pay a formal visit' and wizyta is not in any sense a noun based on the transitive verb wizytować. Hence, its ability to license arguments might be called into question. In any case, the noun wizyta appears more to be an unergative nominal as it may be accompanied only by the nominal corresponding to the 'visiting entity'. The 'visited entity' is optionally realized as a PP headed by the locational preposition $w$ 'in' (wizyt-a papież-a w Polsc-e visit-NOM.SG pope-GEN.SG in Poland-LOC.SG 'the Pope's visit in Poland'). It is, however, doubtful whether the nominal complement of the preposition $w$ 'in' is the argument of the noun wizyta. More generally, the ability of prepositional phrases to introduce arguments of nominals in Polish can be called into question. In fact deverbal nominals whose arguments denote locations, such as odwiedziny 'visit', wizytacja 'inspection', zwiedzanie 'sightseeing', etc. do not introduce the said location arguments by means of prepositional phrases.

Although some studies (e.g. Rutkowski and Progovac 2015) point to the post-nominal position as the typical position for relational adjectives in Polish, Cetnarowska (p. 82) notes that the $\mathrm{A}+\mathrm{N}$ order of the phrase papiesk- $a$ wizyt-a papal-NOM.SG visit-NOM.SG 'papal visit' is much more common than the N+A order, i.e. wizyt-a papiesk-a visit-NOM.SG papal-NOM.SG 'papal visit' ( 84 vs. 47 hits in NKJP). Cetnarowska points to the animacy and topic-worthiness of the nominal base papie $\dot{z}$ 'pope' as the factors contributing to the preference for the prenominal placement of the argumental adjective.

The general conclusion of Cetnarowska's chapter is that relational adjectives are a relatively popular option among other means of realising arguments of deverbal nominal. At the same time, they are visibly less preferred than genitive constructions. Interestingly, thematic relational adjectives are much more common with nominals based on transitive, rather than intransitive, verbs. They also seem confined to relatively formal contexts and written registers. Further research should focus on whether these generalisations reveal some more general grammatical or pragmatic principles or whether they are mere idiosyncratic properties of the nominals arrival and visit and their Polish equivalents. 


\subsection{Derivationally unrelated causatives and anticausatives in Slavic: A diachronic perspective from Old Church Slavonic to present day Russian and Polish}

One of the main claims of Anna Malicka-Kleparska's chapter is that the widely held belief that causative and synthetic anticausative verbs are related derivationally (see Dowty 1979; Levin and Rapaport Hovav 1995; Koontz-Garboden 2009 among many others) does not find confirmation in the data from three Slavic languages: Old Church Slavonic (OCS), Russian and Polish. In fact, very many causative verbs in the three languages do not have corresponding synthetic anticausatives. ${ }^{4}$ This clearly suggests that the two constructions are not related by a rule. At the same time, the status of some examples found in the chapter as causative verbs might be called into question. The definition of causative provided by the author on p. 88 is presented below:

'Causatives are such verbs which describe the situation in which the internal argument of the predication undergoes a change, the change being caused by the external argument of the predication'

In the light of this definition, it is hard to see how Polish verbs such as wydębic 'persuade somebody to give something' or zaślubić 'wed' are causatives. Note that the predicate wydębić takes the entity that is passed onto the agent as the internal argument (marked with the accusative), as in sentence (2) taken from the National Corpus of Polish. At the same time, the entity from which the direct object is obtained is introduced by a PP, typically headed by od 'from'.
Tylko jak wy-dęb-i-ć
od nich
$t-e$
pienią $\dot{z}-k-i ?$
only how out-oak-TH-INF from them-GEN.PL this-ACC.PL.NVIR money-DIM-ACC.PL
'Only how can we persuade them to give (us) the money?'

It is hard to say that the money in sentence (2) undergoes any change, unless we mean the change of the possessor but in that case verbs such as give, take, pass, etc. and their Polish/Russian counterparts all should be treated as causatives.

In addition, it is important to note that Polish verbs such as wydębić 'persuade somebody to give something' or zaślubić 'wed' do not have corresponding synthetic or analytic anticausatives. This is only natural if they are not causatives at all. This being said, the vast majority of verbs enumerated in the chapter are indeed causatives which, as argued by the author, do not possess synthetic anticausative counterparts.

The author adopts a syntactic constructivist approach which does not require every causative verb to have a synthetic anticausative correspondent but, at the same time, accounts for the similarities in the lexical semantics of attested causative - anticausative verb pairs which share a single root.

Perhaps the most interesting claim made in the chapter concerns the realisation of the Active Voice head and the Non-active or Middle Voice head assumed to be found in anticausatives. The author makes a rather unorthodox proposal whereby the Active Voice, as

\footnotetext{
4 The existing gaps are filled by analytic reflexively-marked anticausatives which abound in the three languages.
} 
well as the processual v-heads in OCS causative verbs, are spelled-out by means of the prefix. Unlike in Polish and Russian, verbal prefixes were obligatory in OCS causative verbs. On the other hand, according to the author (pp. 92-93), prefixation was not obligatory and less frequent in OCS synthetic anticausatives. Due to this fact, the author postulates that in anticausatives prefixes realise only the processual v-heads. Under such an analysis the entries for any given prefix could be formulated as follows:

\section{(3) a. $\left\{\right.$ Voice $\left._{\text {[active] }}, \mathrm{v}\right\} \leftrightarrow$ pref \\ b. $\{\mathrm{v}\} \leftrightarrow$ pref}

According to entry (3a) the Active Voice head and the v-head are realised as the prefix. According to (3b), only the v-head is realised by the prefix. The first entry realises causatives, whereas the latter realises anticausatives.

OCS, like all its Slavic descendants spoken nowadays, possessed a large number of prefixes whose distribution with particular verbs was largely unpredictable. Unfortunately, one does not learn from the chapter how the system decided which prefix was actually selected to realise the $\{$ Voice, $v$ \} set (or $\mathrm{v}$ in anticausatives) in particular verbs.

At first sight, the only possible option would be to enrich the entries in (3) to be able to refer to particular roots as their context. (4a) presents the relevant linearisation facts, while (4b) and $(4 \mathrm{c})$ contain suggested vocabulary items. ' $\sqrt{ } \mathrm{ROOT}_{1 / 2}$ ' would actually stand for partially overlapping sets of roots. According to Malicka-Kleparska (pp. 92-93), the V-head is realised as the thematic elements in OCS.
(4) a. Voice $+v+\sqrt{ }$ ROOT $+V$
b. $\left\{\right.$ Voice $\left._{[\text {active }}, \mathrm{v}\right\} \leftrightarrow \mathrm{pref} / \ldots \sqrt{ }_{\mathrm{ROOT}_{1}}$
c. $\{\mathrm{v}\} \leftrightarrow \operatorname{pref} / \ldots \sqrt{\mathrm{ROOT}_{2}}$

The analysis suggested above is not meant to be exhaustive and raises many questions, e.g. 'Why would the Voice + v complex be linearised to the left of the root?'. The most serious problem which renders the reference-to-the-root analysis insufficient (if not plain wrong) is the fact that, in Slavic, a single verbal stem, i.e. a complex of the root and thematic element, may be found with many different prefixes giving rise to different causative verbs, c.f. Polish $z a-k o n c z-y-\dot{c}$ behind-finish-TH-INF 'finish', do-kończ-y-ć to-finish-TH-INF 'finish off, wy-kończ-y-ć outfinish-TH-INF 'exhaust, kill'; $w z$ - $d \nmid u \dot{z}-y$-ć with-long-TH-INF 'lengthen (a sound)', prze-dluz-y$c$ through-long-TH-INF 'prolong', $w y$ - $d t u \dot{z}-y$-ć out-long-TH-INF 'lengthen', etc. Clearly, in the numerous cases of such sets the reference to the root or the stem would not be sufficient to decide which prefix should be inserted.

\subsection{A room with a view: the monostratal view with some room for derivations}

Whereas Anna Malicka-Kleparska's chapter is a voice against derivational relationships between certain constructions coming from within the generative quarters, the chapter by Konrad Szcześniak is a balanced voice in favour of derivational relationships between 
constructions coming from a researcher known for his work within the Construction Grammar paradigm.

Construction Grammar $(\mathrm{CxG})$ is a set of approaches to grammar which reject the dynamic derivational view of syntax characterised by Generative Linguistics and claim that grammatical constructions are basically stored as relationships between form and function, the latter encompassing aspects of meaning and usage.

Two principles of $\mathrm{CxG}$ that the author discusses are the idiosyncrasy of constructions and its strictly monostratal architecture. The former emphasises the arbitrariness of the relationship between the form and function of any given construction, while the latter postulates the rejection of any possible derivational link between even the most intuitively related grammatical constructions.

Szcześniak (p. 125) claims that the extent to which constructions are arbitrary and idiosyncratic has been exaggerated and that this state of affairs stems from the overzealous rejection of levels of derivation. The focus on the idiosyncratic and the playing down of the role of relationships between constructions led to the overlooking of the similarities between them and to the unnecessary complication of the model.

The first set of phenomena that the author uses to illustrate his point is the class of alternations found in English in which two elements of a sentence are allowed to swap places. These are the Ditransitive-Prepositional alternation (5a), the locative alternation (5b), the particle placement alternation (5c) as well as a number of miscellaneous word-order alternations (see e.g. 5d).

(5) a. Chloe sold Chase a book. vs. Chloe sold a book to Chase.

b. Pat loaded the wagon with the hay. $v s$. Pat loaded the hay onto the wagon.

c. throw out the garbage $v s$. throw the garbage out

d. Put all relishes on the table. vs. Put on the table all the relishes.

Under most analyses couched within the $\mathrm{CxG}$ and related frameworks each of the phrases presented in (5) would constitute a separate construction, i.e. a separate form-function association. This is based on the fact (never questioned by the proponents of transformational analyses) that each of them has its own usage, frequency and stylistic load.

According to Szcześniak, such an interpretation not only leads to the multiplication of constructions ad infinitum, burdening the long-term memory, but also misses the generalisation whereby once a speaker acquires one word-order pattern, they are able to correctly produce the alternative pattern.

In his discussion of the treatment of questions in $\mathrm{CxG}$, the author points out that the proponents of the framework treat questions as a 'combination of constructions'. The very notion of 'combination of constructions' seems to be just another way of legitimising the need for dynamic processes within the grammar: the need that most proponents of $\mathrm{CxG}$ and related approaches would readily deny. Szcześniak also notes that treating declaratives and questions as unrelated surface-oriented constructions, each of which must be acquired by the speaker separately, does not allow for the explanation of the absence of the so-called wanna-contraction 
in sentences such as (6a), the classic explanation being the blocking of the contraction by the presence of the trace of who in between want and to (6b) (see Anderson and Lightfoot 2002).

(6) a. ${ }^{*}$ Who do you wanna go?

b. Who do you want $t_{i}$ to go?

The third type of construction discussed in the chapter is the passives. While certain idiosyncratic properties of passives, especially so-called adjectival passives, might suggest that the derivational link between passive and active propositions is decidedly loose, Szcześniak notes that the $\mathrm{CxG}$ approach is incapable of capturing certain important generalisations concerning passives in Slavic languages. To be more precise, Slavic predicates that do not assign the accusative case do not form passives (see 7). ${ }^{5}$
a. Sędzi-a u-wierz-y-ł świadk-owi.
judge-NOM.SG at-faith-TH-PTCP witness-DAT.SG
'The judge believed the witness'
b. ${ }^{*}$ Świadek by- $t \quad u$-wierz-on- $y$.
witness-NOM.SG be-PTCP at-faith-PTCP-NOM.SG
'The witness was believed'

Szcześniak notes that although the observed generalisation does not point to the passives being derived from the surface forms, the constraint clearly points to a link between the active and passive forms of the predicate, a link that the radical $\mathrm{CxG}$ philosophy cannot account for.

The author concludes by claiming that, although an architecture of grammar that relies too much on transformations is not a promising research perspective, a genuinely monostratal architecture in not one, either. He suggests a model which incorporates at least a limited number of, broadly understood, derivations that will make it possible to account for certain obvious affinities between constructions.

What is rather unclear to us is what particular implementation of Generative Grammar the author refers to when writing about 'Chomsky's model of grammar' (p. 122) or what authors he refers to when mentioning 'generative grammarians' (p. 129) and 'proponents of derivational link' (p. 132). Whereas Construction Grammar should be viewed as a reaction to the often unjustifiably lavish Government and Binding generative architecture of the 1980s, one has to keep in mind that Generative Grammar itself had its own response to it. The Minimalist Program of the 1990s and 2000s (Chomsky 1995, 2000, 2008) and its recent outgrowth, the

5 There are some exceptions to this generalisation. In Polish, verbs which assign the inherent Instrumental case, such as zarządzać 'govern, administer' (i), do form passives (see ii).
(i)
Marek dobrz-e zarządz-a majątki-em.
Mark-NOM good-ADV administer-PRS.3.SG estate-INST.SG
'Marek administers the estate well.'
(ii) Majątek jest dobrz-e zarządz-a-n-y przez Mark-a.
estate.NOM.SG is good-ADV govern-TH.PTCP.NOM.SG by Mark-ACC.SG
'The estate is administered by Mark well.' 
Problems of Projection (Chomsky 2013), restrict the transformational apparatus to the operation Merge, which combines sets of elements to form larger sets.

Many pairs of constructions mentioned by the author, e.g. the Ditransitive-Prepositional alternation (5a), the locative alternation (5b), or the passive (especially adjectival passives, see Bruening 2014), are no longer considered to be traditional transformations. As discussed in the previous section, even seemingly basic argument structure alternations such as the causativeanticausative alternations are no longer regarded as transformational by many scholars. The syntactico-semantic affinities between the constructions that traditionally featured as members of 'alternations' are analysed as a function of the same elements or sets of elements (roots, causative Verb Phrases, transitive Voice Phrases) that the pairs of constructions may share.

At the same time, as far as we can see, the formation of wh-questions in languages such as English is still treated as involving movement (Internal Merge) by many scholars (a step that might be dictated by phenomena such as the restrictions on wanna-contraction mentioned above).

It may, therefore, be the case that the 'mixed architecture' model suggested by Szcześniak (p. 138) which incorporates idiosyncratic constructions and regular 'transformations' already exists in the form of the Minimalist Program. It, clearly, differs from the CxG and similar models in that it is not a usage-based model and it has still a modular architecture. Nevertheless, it definitely does justice to the semantico-pragmatic differences between members of alternating pairs such as the ones in (5), and at the same time captures the affinities between them.

\subsection{The information structure of Dative Experiencer psych verbs}

The discussion presented by Rozwadowska and Jiménez-Fernández revolves around psychological predicates in Polish, Spanish and English. Psychological predicates include Subject Experiencer verbs (SE), Object Experiencer (OE) verbs, and Dative Experiencer (DE) verbs. In particular, the authors focus on the discourse functions and syntactic positioning of the arguments of psych verbs. They argue that different Information Structure (IS) interpretations correspond to different word orderings. The claim itself does not seem to be novel, yet the authors draw an interesting distinction between English, Polish and Spanish with regard to the positioning of Dative Experiencers. DEs, according to the authors, do not target a single syntactic position and may value different sets of features.

The experiment in which the authors asked native speakers about their preferences of psych verbs shows that English speakers prefer answers with psych verbs that have an element carrying information focus to its right, i.e. sentence finally. In the case of all-focus sentences, both constructions, i.e. SE and OE constructions, were chosen as possible answers. It does show that IS influences the choice of the psych verb in English. As for Spanish, not all answers provided by the respondents comply with the generalisation made by the authors. For example, the chart in (36) shows that the majority of informants when asked about the Experiencer chose an option in which two answers were equally acceptable; one of them had an Experiencer at the end of the sentence and the other had a Stimulus at the end of the sentence. According to the 
proposed hypothesis, the answer with an Experiencer sentence-finally should be the most popular one. In fact, it was the least popular choice. The results of the experiment also contradict the authors' judgements presented in examples (14-16), which show that the most felicitous answer to the question about the Experiencer is the one with the Experiencer at the end of the sentence. Secondly, when it comes to all-focus sentences, the option with both constructions, i.e. SE and OE constructions, being acceptable was not the most popular choice in contrast to the claims made in the article. The biggest percentage of informants showed a preference towards the Subject Experiencer construction. This exceptional behaviour is not mentioned in the article. As for Polish, some reservations concerning clarity could be raised. The examples presented in (26-28) differ from those used in the experiment and shown in (38-40). Only one of the two possible answers provided in (26) and (27) contains the same verb as the question, which could distort the results of the questionnaire. Speakers in their answers tend to use the same lexical verbs as in the questions they hear. The use of the same verb in questions and answers could produce biased results. The English and Spanish sets of answers contain lexical verbs different from the ones used in the questions. Apart from that, the results of the experiment conducted in Polish overlap with the results obtained for English but not for Spanish. Yet, the authors maintain that the three languages behave in the same way with regard to the choice of the psych predicates.

In Polish and Spanish sentences, DEs can be placed either sentence finally or sentence initially depending on which constituent is in focus. What seems to be an important conclusion drawn in the article is the fact that Spanish and Polish OVS order sentences with DEs are allfocus sentences. Following Erteschik-Shir (2007), among others, the authors maintain that the order in all-focus sentences is an unmarked order. Since Spanish and Polish DEs appear in allfocus sentences with the OVS order, this word order has to be an unmarked order. This is a very interesting observation as the two languages under investigation are known to be SVO languages. The experiment was supposed to confirm those observations. In the experiment with Polish and Spanish the majority of speakers chose the option in which both orders are acceptable. The authors, however, seem to formulate their conclusions on the basis of the other two groups of responses in which only one of the two orders could be chosen. In Spanish each order was equally felicitous, while in Polish it was the SVO order that was more acceptable for the participants of the experiment. Again, it could be argued that the claims made in the text do not always match the results of the experiment presented in the charts. As for all-focus sentences, the preferred order in Spanish was supposed to be OVS. However, the chart in (43) shows that the same percentage of respondents who chose answers with an OVS order chose DE constructions with an SVO order. The majority of speakers picked the option in which both orders are acceptable. In the text, however, the authors argue that it is an OVS order that is the most popular one in all-focus sentences in Spanish. The experiment also shows that Polish does not exhibit a preference towards only one word order in neutral contexts. The majority of Polish informants chose the option that accepts both orders, SVO and OVS, in all-focus contexts. According to the chart in (43), contrary to the claim made in the text, Spanish informants made a similar decision.

Moreover, the sentences in (41-43) do not correspond to the set of sentences presented earlier in (29-31). This different selection of sentences remains unexplained. The same can be 
observed for Polish, except for the identical sentences in (34) and (46). Furthermore, the same lexical verb appears in the questions and in the answers (see (41) and (42) for Spanish and (45) for Polish). As already mentioned, the repetition of the same lexical verb could produce biased results.

The formal analysis presented in Section 6 successfully accounts for the differences between English, Spanish and Polish with regard to the sentential positioning of Experiencers. Rozwadowska and Jiménez-Fernández conclude that DEs move to spec-TP in Spanish while in English and Polish Experiencers target spec-CP if they are discourse marked. In Spanish allfocus sentences, the closest argument of a given DE verb moves to Spec-TP but the movement is not discourse-feature driven. This explanation, however, does not account for the results of the experiment presented in (43), according to which DE constructions with OVS order and SVO order were equally well accepted. It seems that the status of the closest element is not unambiguous. In Polish DE constructions, DEs always move to spec-CP. Yet the analysis presented in (51), in which it is the Stimulus that functions as the information focus remains questionable. The topic feature is valued in the $\mathrm{CP}$ while the focus feature agrees with the [Foc] feature on the same element. Thus, it seems that the Experiencer is both a focus and a topic. The authors also argue that whenever the DE is a topic, the [Foc] feature remains in v. In the structure in (51), however, it is $\mathrm{V}$ and not $\mathrm{v}$ that bears the [Foc] feature. In all-focus sentences both orders, namely OVS and SVO, are equally acceptable. It is either the Experiencer or the Stimulus that functions as an about-ness topic.

The analysis offered by Rozwadowska and Jiménez-Fernández seems to be valid and provides an interesting insight into the nature of Dative Experiencers.

\section{Contrastive studies of words and their meanings}

Whereas the extent to which languages differ in terms of phonological and syntactic computation is a matter of debate, no one has any doubt as to the fact that linguistic systems differ with respect to the content of the lexicon. The second part of the book is concerned with a discussion of different aspects of the study of the lexical resources in different languages. Bożena Duda contributes a case study of the conceptualisation of the term prostitute in languages as different as English, Italian and Turkish. The conceptualisation of the term life in American English, Hungarian and Polish is the subject of the study by Marcin Kuczok. Eleonora Joszko analyses the content of selected general-knowledge dictionaries with respect to the presence of specialised equestrian terms. The chapter by Jacek Rachwał is preoccupied with a comparison of the formal and semantic characteristic of Polish and English house-related technical vocabulary. The presence of English loan translations in the domain of the vocabulary of naming professions is the subject of the chapter contributed by Marcin Zabawa. Finally, Joanna Jasińska-Bryjak and Lucyna Marcol-Cacoń discuss the presence of English-borrowed job titles in the Polish and Italian job markets. 


\subsection{Contrastive analysis of selected synonyms of prostitute in English, Italian, and Turkish}

Bożena Duda's contribution is a contrastive analysis of the synonyms of the basic concept prostitute in three languages: English, Italian and Turkish. An analysis of the etymologies of the expressions synonymous to prostitute allows the author to formulate generalisations concerning the conceptualisation of the names for the occupation under consideration found within a given language.

A closer investigation of the mechanisms of conceptualisation attested in the three languages reveals that the metaphors used in the conceptualization of prostitute involve zoosemy, as is visible in the English words cow, loose fish or Italian falena 'lit. moth', porca 'lit. pig', lupa 'lit. she-wolf', etc. Interestingly, this mechanism is not used in Turkish. Another type of metaphor used in the conceptualisation of prostitute is the foodsemic metaphor SEX IS EATING. This is also illustrated by the English word tart, as well as Turkish kaşer 'lit. cheddar' and lakerda 'lit. pickled tunny'. The foodsemic metaphor mechanism is not attested in Italian. Finally, the metaphor SEX IS A DRIVE/VEHICLE is exclusively a feature of Turkish and is exemplified by words such as çuf̧̧uf 'lit. train' and motor 'lit. engine'.

Two metonymic mechanisms attested in all three languages include the metonymies LOCATION FOR PROFESSION, e.g. Eng. street girl, horizontal, Ita. donna di marciapiede 'lady of the pavement' or Tur. yosma 'pavement flower' and FEATURE FOR PERSON, e.g bad girl, buona donna 'good woman', Tur. paçoz 'lit. bad-looking person'.

Additionally, the three languages under investigation use understatements as well as lexical borrowings to express the concept of prostitute. As noted by the author in the conclusion, the lack of zoosemic metaphors in Turkish and foodsemic metaphors in Italian is one of the most striking differences in the conceptualization patterns observed in the three languages. Other intriguing gaps encompass the lack of the metaphor SEX AS DRIVE/VEHICLE in English and Italian and the absence in English of the conceptualisation based on the idea of 'knowing life' instantiated by the Italian donna di vita 'lady of life' and the Turkish hayatkadını 'woman who knows life'.

This being said, the reasons behind the abovementioned gaps are not explored in much depth within the confines of the chapter. This reflects the general flaw of the onomasiological conceptualisation-based perspective on the structure of vocabulary: it is not predictive but rather abridged to a description emphasising the utmost importance of the obscure culturespecific metapragmatic rules affecting the equivalence and deciding about the degree of overlapping in the conceptualisation patterns attested in languages.

What would certainly be viewed as a scientific advancement in the understanding of the structure of vocabulary and the studies of conceptualisation would be a model that is capable of predicting, on the basis of certain linguistic and cultural variables, whether and to what extent speakers of a given language are likely to utilise particular conceptualisation mechanisms, e.g. a particular metaphor or metonymy. 


\subsection{Precious possession, war or journey? Conceptual metaphors for life in American English, Hungarian and Polish}

Whereas Bożena Duda's analyses the conceptualisation patterns relevant for the concrete notion PROSTITUTE, Marcin Kuczok investigates the conceptualisation of the abstract and fuzzy notion LIFE in three languages: American English, Polish and Hungarian. As indicated by the author, abstract and fuzzy concepts are usually conceptualised by means of metaphors. The aim of this study is to contrast the preference in the use of particular metaphors in the conceptualisation of LIFE in the three relevant languages.

Typical ontological metaphors, i.e. CONCEPT IS ENTITY, used by English speakers comprise LIFE IS A CONTAINER, LIFE IS A GIFT, LIFE IS A BUILDING. English speakers also often resort to structural metaphors, i.e. CONCEPT 1 IS $\mathrm{CONCEPT}_{2}$, such as LIFE IS A GAMBLING GAME, LIFE IS A JOURNEY or LIFE IS A SEA VOYAGE.

According to an empirical study reported in Kövecses (2005), speakers of Hungarian typically utilise structural metaphors such as LIFE IS A STRUGGLE, LIFE IS A COMPROMISE, LIFE IS A JOURNEY, LIFE IS A POSSIBILITY, LIFE IS A PUZZLE as well as an (arguably) ontological metaphor LIFE IS A GIFT. Kövecses assigns the differences in conceptualisation to the differences in the culture and history of the US citizens and Hungarians. Apparently, the latter nation was forced to struggle and participate in military conflicts and thus tends to conceptualise life as a struggle, compromise and possibility.

Kuczok's methodology was to replicate the experiment reported in Kövecses (2005) with the speakers of Polish. 20 native speakers of Polish were asked to provide answers to four general open questions concerning their subjective opinion on life and success. The author classified and calculated the metaphors used by the speakers. The most frequent metaphors used by the participants were: LIFE IS A JOURNEY (appearing 25 times in the answers), LIFE IS WORK/EFFORT (14), LIFE IS WAR/STRUGGLE (12), LIFE IS SCHOOL (12), LIFE IS PRECIOUS POSSESSION (11), LIFE IS CONTAINER (10).

Summarising the results, Kuczok observes that the 'conceptualisation of life in Polish is very serious when compared to (...) American English and Hungarian'. His tentative interpretation of the results is that Polish people conceptualise life as a journey, quest, work, effort and school due to relatively high mobility (many Polish people left the country at the beginning of the $21^{\text {st }}$ century) and the difficult situation in the job market (the high unemployment rate).

As we have mentioned in the previous section, it seems clear that an approach that insists on culture-driven conceptualisation by means of ontological and structural metaphors would benefit from a methodological twist in which the type of metaphors used by the speakers to conceptualise fundamental yet fuzzy concepts such as LIFE, LOVE, GOD, COUNTRY, etc. is predicted on the basis of cultural and socio-economic variables and not simply accounted for post hoc. For some reason, authors investigating conceptualisation opt for the post hoc theorising on the basis of the data observed rather than deducing the preferences for certain metaphors used by the speakers on the basis of such hard data as the migration rate or unemployment rate. Such an approach would certainly render the conceptualisation approach much less speculative and much more empirically interesting. 


\subsection{Inside information: Specialized vocabulary in general-language dictionaries as exemplified by English and Polish equestrian terms}

This chapter examines the presence of equestrian terms in English and Polish general-language dictionaries. The three dictionaries scrutinised by the author with regard to a strictly selected list of equestrian terms are PWN-Oxford English-Polish dictionary (2003), Longman dictionary of contemporary English (2005) and PWN-Oxford Polish-English dictionary (2004). Joszko shows that the general-language dictionaries lack an exhaustive list of equestrian terms. Not all of the terms that can be found in them include a specialised meaning. Others are wrongly defined. All of these point to a great need of lexicographic works with a narrowed, yet specialised, range of vocabulary.

The first part of the chapter describes the relationship between specialised vocabulary, lexicography and translation. Joszko points out how invaluable specialised dictionaries are in the work of translators whose knowledge does not match the expertise possessed by the subject field specialists. Terminology, in contrast to translation, is a static, analytical process immune to loans or direct borrowings that creates a fixed match between concepts and terms. Translation, being the complete opposite, uses it as a tool. The author argues that the relationship between them is not perfect. No concrete examples supporting this view are provided. As for specialised lexicographic works, most of them are passive, providing no context of use. Moreover, they are limited in their scope, leaving translators at a terminological loss. A lack of corpora revealing textual characteristics is another problem translators face. The author concludes here with the view that translation-specialised dictionaries should be managed by generalised translational lexicography (see Zmarzer 1991). The second part of the chapter aims to show whether it actually works in three widely used generalized dictionaries.

Section 10.3 is the most revealing as we learn how the dictionaries mentioned above manage equestrian terminology. The subject matter mistakes observed by the author are not that many. Two out of the three investigated dictionaries contain the same type of mistake. The author rightly highlights the mistake in both dictionaries and provides corrections. The corrections, however, are not supported by other sources apart from the author's own knowledge indicated by the abbreviations of the author's name and surname. In one place, though, on page 176, in Table 1, in the definition of the word canter, Joszko provides the abbreviation E.P. which remains unexplained in the article. Moreover, the title of Table 3, The most frequent English terms in PWN-Oxford Polish-English dictionary (2004), is confusing as the table contains a list of Polish, not English, terms. Each Polish term is accompanied by an English equivalent. Joszko does not provide any source(s) for the equivalents. The author observes that PWN-Oxford Polish-English dictionary contains more terms with equestrian meanings, namely 12, than PWN-Oxford English-Polish dictionary, namely 10. According to Joszko, this supports a common observation that it is more difficult to translate from a foreign language than from one's mother language. This claim seems to be unfounded with regard to the data just quoted. The difference concerns only 2 items, which does not seem to be a significant number. What is more, those 10 items constitute a bigger part of the studied sample (24.4\%) than the other 12 items (17.4\%). It is also difficult to decide unambiguously what could stand behind the difference highlighted by the author. Since terminology, in contrast to translation, is a static 
process of describing terms, the author's mother tongue should not have that much influence on the choice of the terms in question.

Joszko's work provides a valuable insight into the presence and absence of specialised vocabulary in general language dictionaries. Despite the narrow range of the study, important conclusions are drawn that can be tested against further data.

\subsection{A morphological, semantic, and etymological comparison of English and Polish house- related technical terms}

The contrastive analysis presented by Rachfał focuses on house-related technical terms in English and Polish. The architectural lexicons are compared in terms of their morphology, semantics and etymology.

As for morphology, two processes are described in both English and Polish, namely compounding and derivation. Rachfał lists the following popular compounds among English house-related terms.

(8) a. $N+N$ compounds: cornerstone;

b. $N+N+N$ compounds (the first two being themselves a compound): brickwork bond;

c. relational adjectives (RAs) $+\mathrm{N}$ compounds: thermal insulation, thatched roof;

d. $\mathrm{V}+\mathrm{N}$ compounds: flyway;

e. synthetic (verbal) compounds: rough-hewn;

f. synthetic (non-verbal) compounds: dog-legged;

g. synthetic nominal compounds with gerund heads: rafter framing;

h. "combination of deverbal substantive determining a common substantive": dining room;

i. $\quad N+N$ compounds with the head noun being a product of conversion: door reveal;

j. nominal compounds with phrasal modifiers: tongue-and-groove joint;

k. compound adjective $+N$ : side-hung window.

The only thing that could have been elaborated on for the sake of better understanding in this part of the chapter is the meaning of relational adjectives, especially in the case of examples in which the relational adjective is not denominal, e.g. total going. Rachfał also provides a list of prefixes and suffixes that appear with house-related technical terms. From the discussion it can be inferred that the technical terms in question do not exhibit any unusual behaviour as they comply with the observations already made in the literature.

As for Polish, Rachfał notes that the most popular type of juxtaposition is $N+R A$ nominal compounding with the adjectival nonhead placed to the right of the head noun (e.g. kamien wegielny 'cornerstone'. There are also $N+N_{\mathrm{GEN}}$ compounds where the second element bears genitive case (e.g. przypora muru 'counterfort wall'). The former group of compounds accepts word order changes more readily than the latter group. The other group described by Rachfat comprises lexicalised phrases with fixed denotations (e.g. układanie na zaprawie 'bedding'). The last group of compounds contains examples of synthetic compounds (e.g. wiatrołap 'draught lobby'). All types of compounds found by Rachfał are endocentric. The author makes an interesting comparison between the English compound concrete curing and its Polish equivalent dojrzewanie betonu. The former compound contains a deverbal head noun derived from a 
transitive verb while the latter has a deverbal noun derived from an intransitive verb. It would be interesting to examine more examples of this kind from both languages to see whether one can talk about some regularity. When it comes to derivation, house-related nouns in Polish can be denominal (e.g. mur-arka 'brickwork'), de-adjectival (e.g. pust-ak 'hollow brick'), deverbal (e.g. ściag-acz'tie'), of phrasal origin (e.g. namur-nica 'wall plate') and with the diminutive suffix -ek (e.g. stup-ek'small post'). The author does not fail to mention cases of prefixation as a result of which we receive perfective verbs (e.g. pod-niesi-enie 'riser').

The morphological comparison ends with a summary of the general differences between English and Polish. What could be added here is a comparison of the same list of compounds with their equivalents in both languages. It would show how both languages morphologically approach the same compound expressions.

In Section 11.3, we learn about possible semantic analyses of house-related terms. The author discusses the terms with regard to semantic decomposition and lexical relationships. As for semantic decomposition, the author concludes that the analysis proposed by Pustejovsky (1991) accounts for the differences between architectural terms in a more satisfactory way than the one along the lines of Riemer (2010). Although each analysis is presented, we do not see in exactly what way the former is better than the other. Section 11.3.3 deals with a semantic interpretation of compounds. The author starts the discussion by mentioning a well-known inherent ambiguity among $N+N$ compounds. On the basis of Jackendoff (2009), Rachfal shows how such ambiguity can be avoided. However, more attention should be devoted to a detailed explanation of the abovementioned inherent ambiguity of compounds. Some examples would also clarify the discussion and would constitute an important background for the proposed solution.

The last part of the analysis concerns the etymology of architectural terms. It is the most revealing part of the chapter. Rachfal notes that the first group of house-related terms in both languages was borrowed from sister languages, namely English borrowed from Old Norse and Polish from Czech. Later, English absorbed house-related expressions from Old French while Polish from Middle High German.

Without a doubt, Rachfał's chapter constitutes a significant contribution to contrastive studies. It also poses different questions that could lead to more detailed studies of architectural terminologies encompassing more languages.

\subsection{English loan translations in the Polish names of professions}

In this chapter, Zabawa examines the nature of loan translations. The contribution is divided into two parts. First, he focuses on terminological confusion as a result of which it is hard to unambiguously distinguish loan translations from different types of borrowings. Then he narrows down his analysis to the loan translations in the Polish names of professions found in the official list of professions prepared by the Polish Ministry of Labour.

In the first part of his chapter, Zabawa introduces the reader to the definitions of popular types of borrowings, such as lexical borrowings and semantic borrowings. In Section 12.3.1, we learn about the detailed classification of loan translations. Despite being a section with general 
remarks only, it lacks examples, especially, of semi-calques and semi-renditions. They would help the reader follow the terminological confusion mentioned by the author. The following three sections deal with differences between loan translations and semantic loans (Section 12.3.2), loan translations and loan renditions (Section 12.3.3), and loan translations and native phraseological innovations (Section 12.3.4). In Section 12.3.2, on the basis of two concrete examples, Zabawa shows how difficult it is to distinguish between phrases that are only calques and those that are only semantic loans. One of the examples, namely architekt stron internetowych (website architect), has already appeared in Section 12.1, where it is discussed as an example of a semantic loan. In Section 12.4, however, it is categorised as a semi-calque. Presenting the same example from three different perspectives does not help eliminate the confusion. It must be admitted, though that, indeed, some examples do contain features of both semantic loans and loan translations. For the sake of classification, instead of discrediting such examples, the existence of such a group of borrowings that exhibit features of both types could be admitted. Section 12.3.3 shows three ways in which we can recognise the difference between loan translations and loan renditions. One example provided by the author could raise some questions, namely, drapacz chmur (lit. cloud-scraper, modelled after English skyscraper), which is argued to be a loan rendition of the phrase skyscraper. Since cloud is not sky, drapacz chmur cannot be considered a loan translation. That is undoubtedly true and, yet, both phrases considered as a single unit mean exactly the same. A more detailed definition of loan renditions including information about whether we should consider the meaning of the parts of a given phrase or a phrase as a whole would clarify the discussion. Section 12.3.4. provides a very useful set of criteria that illustrate the difference between loan translations and native phraseological innovations. The following section focuses on the difference between semi-calques and lexical borrowings. The reader is presented with a set of examples which may cause confusion but no detailed discussion is proposed. As a result, we are not able to tell what the author considers as a semi-calque and in what respect it differs from lexical borrowings. This would be beneficial from the perspective of one of the following sections, namely Section 12.4, in which some phrases are named semi-calques even though they do resemble lexical borrowings. Section 12.4 provides a list of Polish names of professions borrowed from English. They are categorised by the author as calques, semi-calques, renditions and loan creations. The section ends with an analysis of two examples of calques from the list using the criteria provided in Section 12.3.4. We can see that, indeed, the two phrases chosen by the author have to be calques and not native phraseological innovations. The list, however, could raise some questions. It remains unclear why some phrases are categorised as semi-calques and not lexical borrowings. The example kierownik działu zarzadzania zasobami ludzkimi (human resource manager) in Section 12.4 is classified as a calque but in Section 12.3.2 it is discussed as an example that causes confusion as it complies with the definition of a semantic loan and loan translation. What seems to be an arbitrary classification is not a solution.

Zabawa discusses a challenging area of contrastive analysis. The terminological confusion is clearly explained, and this is, undoubtedly, an important advancement in the analysis of loan translations. 


\subsection{KAM, CEO, HRM: 'who is who' on the job market? A contrastive analysis of foreign job titles in Italian and Polish}

In their chapter Joanna Jasińska-Bryjak and Lucyna Marcol-Cacon present an analysis of the use of foreign job names in Polish and Italian. The aim of the chapter is to investigate to what extent the two languages utilize foreign names to name professions and to what extent they stick to native vocabulary for that purpose.

The material analysed by the authors comprised 2000 job titles. 1000 were collected from job advertisements posted online on two Polish websites: http://gazetapraca.pl/ and http://pracuj.pl/ over the course of two months of 2014. Another 1000 were obtained through an Italian website http://lavoro.corriere.it in the same period.

The analysis of the gathered material showed that frequently the authors of advertisements decide to use the English name without any modification. Additionally, the Polish part of the sample included English names followed by their Polish translations, e.g. Project Manager Kierownik projektu, Accountant - Księgowy/Księgowa, Polish job titles with English elements, e.g. Pracownik w dziale Hotline 'Hotline operator', Kierownik Dziatu Leasingu 'Leasing Division Manager' as well as rare cases of Polish names followed by their English equivalents, e.g. Kierownik Projektu/Project Manager.

Apart from the large number of English loans the Italian part of the sample also contains many bilingual names, e.g. Agenti di commercio - Sales accountant, Addetto Assistenza Clienti - Customer Service, Italian job titles with English elements, e.g. Supply chain manager con conoscenza della lingua tedesca 'Supply chain manager with knowledge of the German language', Licensing manager - settore media entertainment 'Licensing manager in the sector of media entertainment', $P M$ - Esperto in Logistica e trasporti 'PM - an expert in Logistics and transportation'.

The authors note the visible signs of instability of certain borrowings. This is manifested in the Polish part of the sample by an inconsistent spelling of the word manager, which is sometimes spelled as menedzer or menadzer, while on other occasions the original spelling is preserved. An interesting case in Italian is observed in phrases with fluctuating word order: an English Junior Manager and an Italian Manager Junior.

In sum, the authors point out that in many cases English lexemes for the job names found in the compiled material were there due to the lack of Polish and Italian equivalents. There is also a numerous group of job names which were referred to by means of loan-words and which possess Polish and Italian translations. In other words, many of the English job titles found in the sample were not necessary.

It is also noted that the frequent use of English terms is dictated by the different organisation of the companies in the English speaking world and in Poland and Italy. At the same time, the most striking difference between the use of job titles in the Polish and Italian sample is the huge disproportion in the number of English loans in the Polish advertisements $(216 / 1000)$ and in the Italian part of the collected material $(555 / 1000)$. The authors note this difference but do not attempt to investigate what caused it. Does Italian lack the terms to express the relevant job titles? Is the presence of English loans in job titles considered more prestigious among speakers of Italian than it is among speakers of Polish? It would clearly be interesting to 
check whether this discrepancy is accidental by comparing samples from different periods of time.

\section{Contrastive linguistics beyond language forms}

The last part of the collection is entitled "Contrastive linguistics beyond language forms" and contains a miscellaneous collection of studies that did not easily fit into the first two parts. Many of them discuss patterns of language use. Such is the focus of the chapter by Elżbieta MańczakWohlfeld, who analyses attitudes towards the presence of English in Polish scientific discourse. The chapter by Ewa Bogdanowska-Jakubowska discusses the differences and similarities in selfpresentation strategies by analysing the discourse of the debate between politicians representing the two major Polish parties. In her chapter, Paulina Biały highlights the cultural underpinnings of the differences in the use of diminutives by the English and the Polish. Olena Vialikova's contribution focuses on the linguistic and non-linguistic aspects of various types of creolised verse texts in Ukrainian and English. The contribution by Teresa Maria Włosowicz offers a discussion of the category of cognates and how their existence and properties impact on foreign language learning. In the final chapter of the contribution, Victoria Camacho-Taboada, Ángel Jiménez-Fernández and Susana López-Rueda present a detailed study of the acquisition of the presence and absence of surface subject pronouns by speakers of English learning Spanish.

\subsection{English language use in scientific discourse}

Mańczak-Wohlfeld focuses on the role and use of English in scientific discourse. The discussion starts with a closer look at English in three diasporas, each marked with a different status of English, namely English as a native language, English as a second language and English as a foreign language. The statistics provided by Mańczak-Wohlfeld show the popularity of English in each diaspora. We learn that generally English is spoken by 2 billion speakers. The author stresses that each diaspora speaks a different English. In the same section, the author presents her own modified model of the spread of English. Instead of diasporas, we have three circles: the Inner Circle, the Outer Circle, and the Expanding Circle. The Inner Circle sets the norm, the Outer Circle develops the norm while the language of the Expanding Circle depends on the norm. The author classifies the English used in Poland as one that belongs to the Expanding Circle.

The next part outlines the history of the use of English in scientific discourse. The author presents the statistics of different authors showing how the role of English has changed with time in scientific discourse. Between 1890 and 2007 the popularity of English increased significantly. Not only do we learn that English has gradually overtaken German, but we also see in which aspects of scientific discourse English has dominated other languages. As a possible explanation for the popularity of English in original research, exact sciences and theoretical linguistics as opposed to surveys, the humanities, and applied sciences, the author mentions its international character. The reader assumes that what is meant by the international character 
is its world-wide accessibility. However, we do not see how, for example, it accounts for the applied sciences.

Section 14.4 concerns Polish academia. The author argues that Polish scholars working in exact sciences, natural sciences, and technical sciences prefer English while those who specialise in the humanities and social studies choose their native language as the language of scientific discourse. In the next part of this section, the author presents the results of a research study carried out among students of English and Polish philology. The author argues that it would be difficult to conduct such a study among academics. This, however, is not supported by any argument. At the very beginning of this section the author provides opinions of scholars who argue in favour of the use of Polish in scientific discourse. The answers provided by students do not seem to be conclusive, which may be connected with the methodology undertaken in the study. The question posed in the study was the following: what do you think about the use of English in scientific texts in the following fields: the humanities, social studies, exact studies, natural sciences and technical sciences. The results among students of English philology were presented in the following way: 16 opted for publishing only in English, 9 for English and Polish publications within the humanities and social studies, 2 considered Polish to be used as the only academic language (p. 240). It remains unclear why students who were asked about English provided answers that included both English and Polish or only Polish. According to the author, the results are slightly different from what was expected. The reader may be confused as the claims made in this section concerned scholars and not students, so it remains unclear what expectations the author has in mind.

In the last section of the chapter, the author expresses her opinions on the use of English in academic discourse. According to Mańczak-Wohlfeld, researchers who focus on the exact sciences and the technical sciences should write and present their papers in English. This standpoint is supported by the general tendencies reported by different authors concerning the increasing popularity of English. However, researchers that specialise in the social sciences and the humanities present a more complex issue. They should turn to Polish if they write about, for example, grammatical gender which exists in their native language but is absent in English. If they discuss local matters with a target of local and not an international audience, they should also publish in Polish. The author admits that this may be a controversial point of view. Indeed, it may be considered quite difficult to determine what is of a local and not international interest. The border between them is unclear. It could be argued that the development of science is not dependent that much on the extent of the research area covered by a single author as on the availability of the sources made possible thanks to a lingua franca. Grammatical gender in Polish can be knowledgeably described in English using glosses. English does not cause that much of a problem here. It appears that, considering the well-known popularity of English, every scholar realises that publishing in their native language limits the audience to the local one. Translation, with its usual limitations, is a useful tool everyone can always turn to if one targets an international audience. Other drawbacks of publishing matters of local interest only in English remain unknown.

The chapter written by Mańczak-Wohlfeld brings to light an interesting aspect of using English in academic discourse, namely the division between the exact sciences, on the one hand, 
and the humanities and social sciences, on the other. It ends with useful pieces of advice for scholars from both fields.

\subsection{Differences in self-presentational patterns: A community-of-practice perspective}

The chapter by Ewa Bogdanowska-Jakubowska is one of the few contributions that do not focus on comparing sets of data from more than one language, but rather highlight a different dimension of contrast. In her contribution the author analyses different self-presentation strategies visible in the discourse used by representatives of the two major Polish political parties: Civic Platform (pol. Platforma Obywatelska, PO) and Law and Justice (pol. Prawo $i$ Sprawiedliwość, PiS).

The theoretical perspective assumed in the study encompasses the Critical Discourse Analysis (see e.g. Wodak 2011) and the post-modern/discursive approach to face and (im)politeness (Watts 2003, 2005). The Critical Discourse Analysis approach defines discourse as a form of social practice and recognises and highlights the interaction between situations and events and social structures which constitute the frame for the relevant situations and events. The assumption about the continuous interaction between the social and the linguistic which is the foundation of the Critical Discourse Analysis approach implies that the careful analysis of discourse allows us to formulate claims about the self-presentation style of its participants.

The post-modern/discursive approach to face and (im)politeness underlines the social importance of face. Accordingly, face is not so much a property assumed by an individual as it emerges or is created in the course of social interaction. Similarly, (im)politeness is no longer thought of as the property of isolated phrases or sentences but rather as emerging as a result of interaction: it is considered to be a social practice.

The author proposes treating political parties as strictly defined Communities of Practice (see Mills 2011). Like all communities of practice, political parties have: (i) their particular domains of interest, i.e. their members share a worldview and ideas as to how countries should be administered; (ii) the community: party members engage in important activities together, support each other and learn from each other; (iii) the practice: members of a particular party develop or adopt the same tools of social interaction with voters as well as political opponents. According to the author, the particular community membership is reflected in the discourse. In particular, it is manifested in the way they engage in negotiating relationships and face.

In the empirical part of her work the author analysed the discourse of a TV interview with the politicians managing the electoral campaigns in the 2014 European Parliament elections. Tadeusz Zwiefka was the campaign manager for PO, while Andrzej Duda managed the PiS's campaign.

In her conclusions, Bogdanowska-Jakubowska notes that both politicians use the same strategies of self-representation (presenting the party in good light, stressing the positive attributes of their party, explaining their actions and words by the general agenda of the party, non-verbal behaviour) but implement them in a different way.

Whereas Zwiefka is promoting a composed, logical and cultivated image of himself and the party, i.e. community-of-practice, that he represents, Duda is more emotional, often resorts to 
understatements, makes exclamations and accusations. He tends to display satisfaction at his opponents' failure. According to the author, both politicians construct their face in the way typical of the members of PO and PiS, although certain individual traits should also be taken into consideration.

Let us observe that none of the images and the complex strategies used in manifesting them seem to be more effective than the other in the context of Polish political life. Both the parties achieved the same result in the said 2014 European Parliament election (19 members in the EP). The 'logical and composed' face of PO allowed them to win two parliamentary elections in Poland $(2007,2011)$, while the 2015 election was a triumph of the 'emotional' face of PiS, which is the ruling party at the time of writing of this review. While Zwiefka has continued his work in the European Parliament since 2004, Duda has been elected the President of Poland in 2014. It seems, therefore, that the 'composed and logical' face of PO and the 'emotional' face of PiS are not decisive factors in influencing the opinions of Polish voters.

\subsection{The English and the Poles: Two different cultures, two different approaches to the use of diminutives}

The chapter by Biały is based on the assumption that the use of diminutives in a given language is connected with the culture of that language. The comparison between English and Polish culture is to account for the differences in the use of diminutives between the two languages.

A significant number of sources presented by the author supports the claim on the strong relationship between cultures and languages. The author starts the discussion by describing features of English and Polish culture.

English culture represents an individualistic culture of a masculine nature rather than a feminine or childish one. It is more reserved than other cultures. This, according to the author, explains a glaring poverty of diminutive forms. The section ends with a quotation from Fox (2005), according to whom English culture does not seem to value children to the same extent as other cultures do. The author does not comment on what appears to be a rather controversial statement, as affection can be expressed in a variety of ways, not only a linguistic one. Polish culture, on the other hand, is a collective one of a feminine nature that is more emotional than English culture. This, in turn, is reflected in the widespread use of diminutives. The author addresses the issue of diminutives not only as a means of referring to size but also as a means of showing an attitude to the world. For example, we learn that by using diminutive forms Polish hosts show their hospitality that encourages guests to eat more. In such a case guests do not appear to be greedy. In conversations between buyers and sellers diminutives are used as a persuasive strategy which shows respect towards a customer. The author supports each observation with relevant sources. As pointed out by the author, the not uncommon overuse of diminutive forms in Polish, however, may be also interpreted as offensive or even insincere by addressees.

In the last part of the chapter the author presents the results of her own research in which a group of Polish and English native speakers were asked to comment (describe feelings, suggest functions and meanings) on the use of diminutives in a given sentence. The results, however, 
seem to be unclear. For example, the author maintains that $22.5 \%$ of the Polish respondents negatively evaluated a sentence with diminutives referring to food while the whole group argued that it sounded natural. If $22.5 \%$ of the respondents have negative feelings about a sentence, it is hard to imagine how the whole group was satisfied with it. The problem lies either in the results themselves or in the lack of clarity with regard to the evaluation criteria. It transpires from the text that 'negative evaluation' (artificiality, over-exaggeration) has nothing to do with 'naturalness', which is counterintuitive. As for English, the author observes that the same number of respondents interpreted the same sentence in two completely different ways. For the first group, diminutives implied a lack of problem on the part of the host, suggested that the guests are not greedy or minimised the effort of the host. For the other group, the diminutives in the same sentence referred only to size. One cannot fail to observe that the same two interpretations of diminutives were described by the author in Section 16.3.3.1 that referred only to Polish. It could have been stressed at some point that the same two interpretations (one showing attitude and the other a literal one) are also possible in English, yet to a different extent than in Polish.

This chapter presents a valuable collection of sources on the relationship between culture and language and the way this relationship has an influence on the use of diminutives. No doubt culture and language are intertwined, yet one cannot forget that the structure of a given language has an equally decisive role in the usage of a given linguistic form.

\subsection{Semiotic structure of the creolized verse text}

Vialikova examines Ukrainian and American poetic texts that combine verbal and non-verbal components. Generally, this chapter is well structured as it starts with a theoretical background and then proceeds to the analysis of specific texts. However, there are too many mental shortcuts which make the text less approachable for a reader.

In the Introduction the author mentions criticism of Peirce's taxonomy of sign systems but the link between this criticism and the methodological basis in the same line in the text is too indirect, especially for an introduction. The author then draws attention to the inseparable relationship between semantics and pragmatics and between semantics and syntax. This is followed by a something of a conclusion that underlines the interaction between semantics, syntactics and pragmatics in the lingvosemiotic analysis. It remains unexplained, though, why this tripartite structure makes the semiotics 'a system of a special kind' (p. 281). In one of the sections in the Introduction, Vialikova discusses Lotman's (2010) image of semiotic space as multi-layered complex relationships. The author's interpretation of Lotman's image also remains unclear, as reality at one point forms a separate layer of the whole while later we learn that reality is beyond the layers. In another section of the Introduction, the author uses the phrase 'similar problems' although no clear reference to any problems was made in the text before. Neither do we learn what the author means by 'cyber methods' (or 'macrosing' in Section 17.2). The next paragraph also generates confusion. The reader may find the difference between the analysis of the creolised verse text and the interpretation of the text-in-text hard to understand. The author does not elaborate much on the latter concept, hence its doubtful 
contribution to the whole analysis. In sum, the Introduction mentions many aspects of text analysis but it is hard to see any logical train of thought behind them or any direct contribution from the point of view of what follows.

The second part of the chapter presents three models of creolised verse texts: concrete poetry, shape poetry and zaum poetry. The research method chosen by the author is the semiotic study of texts (text as a sign system) with an analysis of the syntactic, semantic and pragmatic relationships between verbal and non-verbal signs. In the same section, the author describes the types of analyses undertaken when creating lingvosemiotic models of creolised verse texts. These are a component analysis (the elicitation and structural organisation of units) and systemic (and not 'systematic' or 'system' as called by the author) functional analysis. Another method used in the analysis is the so-called contextually-interpretive method that positions a given text in relation to other texts. The description of the approaches and methods appears to be a necessary introduction to the analysis of the particular texts.

The first text analysed by the author represents shape poetry in Ukrainian. The description of the syntactic level remains unclear. This may be caused by the unfortunate use of the word 'sequentially'. The author calls some links paradigmatic and syntagmatic but does not provide much explanation. The table which describes the model does not help either. It is hard to see how the snake and the apple form a syntagmatic link. The pragmatics level, as well as the level of semantics, are well outlined.

Another poem analysed by the author is a concrete poem. This time, the verbal and nonverbal signs at all three levels of lingvosemiotic approach are well explained. The name of the concrete poetry is not that obvious, as is the case with the shape poetry. The author could also pay more attention to details. The poem on page 287 contains an octagon and not a hexagon.

Zaum poetry is often connected with confusion. The verbal and non-verbal signs are briefly described at the semantic and pragmatic level. The author fails to explain the signs at the syntactic level which require clarification. In the text preceding the analysis of the poem, there are concepts which do not seem to contribute much to the understanding of zaum poetry. For example, the author mentions a 'letter tradition' which remains unexplained or the fact that 'that game and poetic (bri)colage are biased for Honchar creavity'. Much more attention should be devoted to the poem itself.

In sum, the information on the Ukrainian creolised verse texts contained in the tables is too condensed. The elaboration on the signs in each stage of the model would facilitate the reader's comprehension of the author's analysis. What is more, the Ukrainian poems should be accompanied by English translations. Otherwise, non-speakers of Ukrainian will find it hard to verify the author's observations.

In the last part of Section 17.2, Vialikova analyses three American creolised verse texts. As for the shape poem, the author observes a lack of rhyme in contrast to the Ukrainian shape poem. As rhyme was not discussed earlier in the text, it is hard for a reader to relate to it in any way. Generally, though, the lingvosemiotic analysis of all three examples of different types of American creolised verse texts is carried out in a clear way.

All in all, the chapter by Vialikova presents an interesting perspective on the analysis of creolised verse texts. Even though the discussion does refer to two languages, no space is devoted to a comparison of creolised verse text in English and Ukrainian. Apart from the 
rhyme, we do not learn much about the differences or similarities between Ukrainian and American creolised verse text. The Conclusion which appears to be a general summary of lingvosemiotic analysis does not help either.

\subsection{Cross-linguistic similarities and differences between cognates and implications for foreign language learning}

Włosowicz’s chapter discusses formal differences between cognates. It adopts an interesting perspective on cognates which are most often associated with a common overlap among languages and the facilitation of a foreign language learning.

In Section 18.2, the author presents the reader with a definition of a cognate which is much broader than the traditional definition, namely that cognates should be linked not only to semantic properties but also to formal ones and, as a category, they encompass cognates of common origin, borrowings and internationalisms. The similarities between cognates are an advantage in foreign language learning. In the middle of the section, however, the author presents a different side of cognates. False friends, for example, also share formal similarities but semantically they do differ. The recognition of similarities and differences, despite its learning potential, very often requires the use of awareness-raising activities as not all learners find them that obvious. The successful recognition of cognates is often hindered by graphemic differences and depends more on phonological differences. The paragraph ends with a statement that is hard to relate to the rest. It states that the understanding of languages from the same language family can be difficult due to differences in vocabulary. The direct contribution of this statement is doubtful. The author refers to Section 18.4 as a discussion on formal and semantic similarities between cognates. We cannot agree that this section deals with similarities. The author's title for this section ('Cognates as a special area of vocabulary') much better reflects its content.

Section 18.3 begins with a discussion of Lado's (1957) Contrastive Analysis Hypothesis $(\mathrm{CAH})$, under which learning difficulties can be predicted from the comparison of languages. Włosowicz refers to sources that show how similarities among closely related languages may, in fact, cause learning difficulties. Czech learners of Russian and English when using Russian may make mistakes that are based on the similarities between the two Slavic languages. Since those types of mistakes are less evident, they are more likely to result in a fossilized interlanguage. The author also points out that similarities among languages do not guarantee facilitation as language learners expect languages to be different, hence their intentional avoidance of similar constructions. The section ends with a pedagogical implication under which the results of contrastive analysis should be adapted before their implementation in the classroom.

The next section is an illustration of the formal and semantic differences between cognates. The author looks at their morphological, orthographical, syntactic, morphosyntactic, semantic and phonological properties.

The section on morphology shows how morphological differences in given cognates may lead either to the use of interlingual blends or to the use of non-target cognates. The pair of 
languages from which examples were taken should have been provided much earlier in this section. As for didactics, the author argues that morphological differences should be taught explicitly. The author could elaborate on the teaching methods regarding morphological differences as they do not seem to be that obvious. As for orthography, similar difficulties arise from the similarities between cognates. Learners produce either non-target or interlingual blends.

Before the presentation of mistakes that arise due to syntactic and morphosyntactic properties, the author usefully explains what she means by those properties. The former refer to the selection of prepositions by verbs. Table 4 on page 303 gives German and English examples of the syntactic differences between semantically identical cognates. The German prepositions in the table, as well as in the text, should be accompanied by their English translations for the sake of a better comparison by the reader. No comment is made here with regard to the process of learning. As for semantics, the author underlines the existence of false friends and partial false friends that may lead to confusion on the part of the learner. The phonology of cognates presents some regularities but there are also unpredictable differences. The author also mentions interlingual homophones, which may lead to serious mistakes among learners.

It is interesting that the contrast made by the author does not only include languages from the same language families but a cross section of languages from different language families. The author touches upon a complex topic from the point of view of linguistics and didactics. Differences among cognates are discussed in more detail than the implications for foreign language learning. This chapter is certainly a worthy contribution to the theme of this volume.

\subsection{The acquisition of null/explicit subject pronouns in Spanish as L2 by English speakers}

This chapter looks at the distribution of null and explicit subject pronouns in the interlanguage of English learners of Spanish.

In the introduction the authors emphasise the fact that null pronouns have been approached from different angles. They, however, take a discourse-oriented point of view which is less well-known than the traditional generative one based on different aspects of agreement. We learn that the distribution of null/explicit pronouns in Spanish depends on verb morphology and discourse factors. The authors focus in detail solely on the latter. Four hypotheses are laid down to be verified by the results of the tests designed by the authors.

The title of Section 19.2 can be a bit confusing with regard to its content. It refers to the acquisition and use of null/pronominal subjects in L2 Spanish. The section, however, elaborates on formal European and Spanish recommendations concerning the development of discourse competence. More importantly, the Spanish adaptation of the CEFR explicitly mentions the use of null/overt subjects. In addition, the authors state that they are the first to conduct a purely Information-Structure based analysis of null pronouns from the point of view of their acquisition. The use of explicit pronouns is not discussed here.

Section 19.3 contributes significantly to the whole chapter. The authors present definitions of different types of topics and foci. One has the impression, though, that each definition lacks 
a comment on whether the given topic/focus is usually null or explicit in Spanish. This would give the reader a fuller picture when it comes to different discourse categories in Spanish. Moreover, the addition of glosses could eliminate some confusion with regard to, for example, sentence (1) where the English translation has the Aboutness-Shift Topic while its original Spanish sentence appears to be missing it. The section ends with a table with features of different discourse categories. Generally, it turns out to be a useful summary. Yet a question arises about the feature specification of C-Focus (contrastive focus) which is marked with the positive value of the feature 'given'. In Section 19.3, it is noted, however, that contrastive focus may refer either to a shared piece of information or it may represent a new piece of information. Thus, it seems that it should be marked in the same way as C-Topic (Contrastive Topic) or AS-Topic (Aboutness-Shift Topic), namely with a plus and a minus.

Section 19.4 presents the methodology and results of the tests. The experiment was conducted among a varied group of English learners of Spanish. The variety of respondents is impressive. There were four groups of English learners divided according to their level of proficiency in Spanish. An acceptability judgement test was the first test. The results are clearly presented. What is interesting is that the authors do not only focus on acceptability judgements but also provide a scale of learning difficulty. There are some points that could be improved, though. Firstly, on page 320 the authors state that in Figure 2 the curve of the $4-5$ value has dashes. Yet, the curve of the 4-5 value in Figure 2 on page 321 is a line and it does not have dashes. In the descriptions of diagrams no reference is made to Figure 9a. Furthermore, for the sake of clarity, the authors could explain the presence of question marks next to some of the discourse categories. The table summarising the results on page 324 contains shaded cells, which could also be clearly explained. The scale of learning difficulty concerning the recognition of non-felicitous answers differs from that presented in the conclusion (Section 19.5) as the latter contains question marks while the former lacks them. The second test involved a translation task. Again, the authors present the results using diagrams and commenting on the scale of difficulty. Interestingly, they observe that, as for G-Topics, most students and near-natives drop explicit subject pronouns more often in subordinate clauses than in the main clauses. This is ascribed to transference errors without any further explanation of what is meant by this in the context of the English-Spanish pair of languages.

The last section of the chapter verifies the hypotheses proposed at the beginning of the chapter. The only unclear conclusion is reached with regard to hypothesis 2 (H2) in which the authors state that 'students get good results when they have to evaluate a sentence with NS but not when they have to do it with explicit ones.' Nowhere in the text do the authors make a similar observation. Neither does any diagram with test results seem to confirm this.

In general, the chapter provides a valuable insight into the interlanguage of English speakers of Spanish. It certainly contributes to the field of contrastive studies, unveiling a novel discourse-related perspective on the use of null/explicit pronouns between typologically different languages. 


\section{Concluding remarks}

To conclude, it must be said that each contribution of the collection is a valuable and important voice within the relevant domain represented by its author(s). The division of the book into three parts gives it the required coherence and makes it more accessible to potential readers. At the same time, the title of the third part 'Contrastive Linguistics beyond Language Forms' is a bit misleading as the contributions by Olena Vialikova, Teresa Maria Włosowicz and Victoria Camacho-Taboada, Ángel Jiménez-Fernández and Susana López-Rueda partially or entirely focus on different aspects of linguistic form or formal aspects of the languages under consideration. In addition to that, although all the contributions are valuable from the point of view of the respective domains that the contributors represent, few of them can be considered to be genuine contributions to linguistics as a contrastive discipline. One would expect some of the chapters to contain proposals concerning novel methods of carrying out comparative analyses across languages or to address current controversies concerning cross-linguistic diversity. Certain fundamental questions such as why languages differ, what is the cause of the geographical diversification of linguistic systems and how to account for it, what is the source of language change and how to model it, have not been asked. To our mind, the proposals concerning these fundamental issues deserve a place in a volume devoted inter alia to the crosslinguistic variation.

This being said, Various Dimensions of Contrastive Studies is a diversified and wellplanned collection of highly stimulating and inspiring contributions. Certainly worth recommending to any linguist who desires to stay in touch with up-to-date trends within the formal as well as functional approaches to language analysis.

\section{References}

Anderson, Stephen R., and David W. Lightfoot. 2002. The Language Organ: Linguistics as Cognitive Psychology. Cambridge: Cambridge University Press.

Beard, Robert. 1995. Lexeme-Morpheme Base Morphology. Albany, NY: SUNY Press.

Beard, Robert and Mark Volpe. 2005. Lexeme-Morpheme Base Morphology. In Pavel Štekauer and Rochelle Lieber (eds.), Handbook of Word-Formation, 189-205. Dordrecht: Springer.

Bloch-Rozmej, Anna. 2008. Melody in Government Phonology. Lublin: Wydawnictwo KUL.

Bloch-Trojnar, Maria. 2013. The mechanics of transposition. A study of action nominalisations in English, Irish, and Polish. Lublin: Wydawnictwo KUL.

Bruening, Banjamin. 2014. Word formation is syntactic: Adjectival passives in English. Natural Language and Linguistic Theory 32: 363-422.

Chomsky, Noam. 1995. The minimalist program. Cambridge, MA: MIT Press.

Chomsky, Noam. 2000. Minimalist inquiries: The framework. In Roger Martin, David Michaels and Juan Uriagereka (eds.), Step by Step, 89-115. Cambridge, MA: MIT Press.

Chomsky, Noam. 2008. On Phases. In Robert Freidin, Carlos P. Otero and Maria Luisa Zubizarreta (eds.), Foundational Issues in Linguistic Theory. Essays in Honor of Jean-Roger Vergnaud, 134-166. Cambridge, MA: MIT Press.

Chomsky, Noam. 2013. Problems of Projection. Lingua, 130, Special Issue "Core Ideas and Results in Syntax". 3349.

Dowty, David. 1979. On the syntax and semantics of the atomic predicate CAUSE. Papers from the 8th Regional Meeting. Chicago Linguistic Society, 62-74. 
Erteschik-Shir, Nomi. 2007. Information Structure. Oxford: Oxford University Press.

Fox, Kate. 2005. Watching the English: The hidden rules of English behaviour. London: Hodder and Stoughton Ltd.

Harris, John. 1994. English sound structure. Oxford: Blackwell.

Jackendoff, Ray. 2009. Compounding in the parallel architecture and conceptual semantics. In Rochelle Lieber and Pavol Štekauer (eds.), The Oxford handbook of compounding, 105-128, Oxford: Oxford University.

Kaye, Jonathan, Jean Lowenstamm and Jean-Roger. Vergnaud. 1990. Constituent structure and government in phonology. Phonology (7): 193-231.

Knight, Chris. 2016. Puzzles and mysteries in the origins of language. Language and Communication 50: 12-21. Koontz-Garboden, Andrew. 2009. Anticausativization. Natural Language and Linguistic Theory 27: 77-138.

Kövecses, Zoltan. 2005. Metaphor in culture. Universality and variation. Cambridge: Cambridge University Press. Lado, Robert. 1957. Linguistics across cultures. Ann Arbor, MI: The University of Michigan Press.

Levin, Beth and Malka Rapaport Hovav. 1995. Unaccusativity: At the syntax-lexical semantics interface (Linguistic Inquiry Monograph 2). Cambridge, MA: MIT Press.

Longman Dictionary of Contemporary English. 2005. 4th ed. With Writing Assistant. Harlow: Longman.

Lotman, Yuri. M. 2010. Semiosfera. St. Petersburg: Iskusstvo.

Mills, Sara. 2011. Discoursive approaches to politeness and impoliteness. In Linguistic Politeness Research Group (eds.), Discoursive approaches to politeness, 19-56. Berlin-Boston: De Gruyter Mouton.

Pustejovsky, James. 1991. The generative lexicon. Computational linguistics 17(4): 409-441.

PWN-Oxford English-Polish dictionary. 2003. Warszawa: Wydawnictwo Naukowe PWN.

PWN-Oxford Polish-English dictionary. 2004. Warszawa: Wydawnictwo Naukowe PWN.

Riemer, Nick. 2010. Introducing semantics. Cambridge: Cambridge University Press.

Rutkowski, Paweł and Ljiljana Progovac. 2015. Classification projection in Polish and Serbian: The position and shape of classifying adjectives. In Steven Franks, Frank Y. Gladney and Mila Tasseva-Kurktchieva (eds.), Formal approaches to Slavic linguistics: The South Carolina meeting 2004, 289-299. Ann Arbor, MI: Michigan Slavic Publications.

Scheer, Tobias. 2004. A lateral theory of phonology. Vol. 1: What is CVCV, and why should it be? Berlin: Mouton de Gruyter.

Scheer, Tobias and Markéta Zikova. 2010. The Coda Mirror v2. Acta Linguistica Hungarica 57: 1-21.

Wodak, Ruth. 2011. The discourse of politics in action. Politics as usual. Basingstoke: Palgrave Macmillan.

Watts, Richard. 2003. Politeness. Cambridge: Cambridge University Press.

Watts, Richard. 2005. Linguistic politeness research: Quo vadis? In Richard J. Watts, Sachiko Ide, and Konrad Ehlich (eds.), Politeness in language. Studies in its history. Theory and practice. 2nd edn., 43-69. Berlin: Mouton de Gruyter.

Zmarzer, Wanda. 1991. Leksykografia terminologiczna. In Franciszek Grucza (ed.), Teoretyczne podstawy terminologii, 117-132. Wrocław: Zakład Narodowy im. Ossolińskich. 